\title{
Evaluation of the circulating level of fibroblast activation protein a for diagnosis of esophageal squamous cell carcinoma
}

\author{
Yuehua Liao ${ }^{1, *}$, Shan Xing ${ }^{2, *}$, Banglao $\mathrm{Xu}^{3}$, Wanli Liu' ${ }^{2}$, Ge Zhang ${ }^{1}$ \\ ${ }^{1}$ Department of Microbial and Biochemical Pharmacy, School of Pharmaceutical Sciences, Sun Yat-Sen University, University \\ Town, Guangzhou, China \\ ${ }^{2}$ Department of Clinical Laboratory Medicine, Sun Yat-Sen University Cancer Center, Guangzhou, China \\ ${ }^{3}$ Department of Clinical Laboratory Medicine, Guangzhou First Municipal People's Hospital, Guangzhou Medical University, \\ Guangzhou, China \\ *These authors contributed equally to this work
}

Correspondence to: Ge Zhang, email: zhangge@mail.sysu.edu.cn

Keywords: FAPa, esophageal squamous cell carcinoma, plasma, diagnosis biomarker, ELISA

Received: September 26, $2016 \quad$ Accepted: March 09, $2017 \quad$ Published: March 16, 2017

Copyright: Liao et al. This is an open-access article distributed under the terms of the Creative Commons Attribution License (CC-BY), which permits unrestricted use, distribution, and reproduction in any medium, provided the original author and source are credited.

\section{ABSTRACT}

To evaluate whether circulating fibroblast activation protein a (FAPa) could serve as a biomarker for the diagnosis of esophageal squamous cell carcinoma (ESCC), enzyme-linked immunosorbent assay (ELISA) was used to detect plasma FAPa in 556 participants including ESCC group, benign esophageal disease group, healthy controls and other cancer controls group. The levels of plasma FAPa were significantly decreased in ESCC patients $(P<0.001)$ and showed a positive correlation with HDL-C levels $(R=0.372, P<0.001)$. The sensitivity and specificity of plasma FAPa were $56.1 \%$ and $85.6 \%$ based on the optimal cut-off $(49.04 \mathrm{ng} / \mathrm{ml}$, AUC $=0.714)$. The combination of FAPa and the traditional biomarkers (CEA, CYFR211 and SCCA) improved the sensitivity $(41.5 \%)$ without compromising the specificity $(95.0 \%)$. Contradictorily, the immunohistochemical staining revealed the overexpression of FAPa in stroma of ESCC tissues. So the source of soluble FAPa was further explored by qRT-PCR, Western blotting, ELISA and immunoprecipitation in fibroblast cell lines and mouse xenograft models. We found that the plasma FAPa was not correlated with the FAPa expressed in tumor, and the multi-organ might contribute to the circulating levels of FAPa including skeletal muscle, liver and bone marrow. These results indicated that the low plasma FAPa level might due to the systemic reaction to the presence of tumor and circulating FAPa level might be a potential indicator for diagnosing ESCC.

\section{INTRODUCTION}

Esophageal squamous cell carcinoma (ESCC) is one of the most aggressive gastrointestinal cancers in China [1]. It has a very high mortality rate due to the relatively late stage of diagnosis [2]. Currently, traditional tumor markers, such as CEA, CYFRA211 and SCCA, are used to diagnose and evaluate ESCC progression. However, these tumor markers exhibit a low sensitivity in detecting ESCC. Therefore, there is an urgent needed to explore valuable tumor markers for ESCC detection [3].

Recently, circulating fibroblast activation protein $\alpha(\mathrm{FAP} \alpha)$ shows good specificity for colorectal cancer (CRC) diagnosis, and the combination of FAP $\alpha$ and other multiple markers all show high sensitivity for early detection of CRC [4-5]. Circulating FAP $\alpha$ levels were demonstrated significantly lower in cancer patients compared with healthy subjects and correlated inversely with survival in most types of cancer [6-9]. However, the circulating FAP $\alpha$ level in ESCC is still unclear.

FAP $\alpha$, also known as seprase, has long been known to be expressed in the cancer associated fibroblasts of tumor stroma, and plays multiple roles in neoangiogenesis, invasion, and metastasis [10-12]; FAP $\alpha$ has been investigated as an invasion biomarker in various cancers, and has also been explored as a target for cancer therapy [13-14]. Multiple studies have confirmed that the expression of FAP $\alpha$ was upregulated in ESCC tissues [15]. Contradictorily, $\mathrm{FAP}^{+}$stromal cells are found to be 
present in the multiple normal tissues and organs [16-17]. Besides, soluble form of FAP $\alpha$ in human blood (also named antiplasmin-cleaving enzyme, APCE) was reported to play a role in fibrinolysis [18]. Until now, little is known about the exact origin of circulating FAP $\alpha$.

In the present study, we measured the plasma FAP $\alpha$ level in cancer patients and investigated the associations between circulating FAP $\alpha$ and patients' clinical outcomes to evaluate the clinical value of plasma FAP $\alpha$ as diagnostic parameter in ESCC patients.

\section{RESULTS}

\section{Plasma FAP $\alpha$ level was reduced in of ESCC patients}

Plasma levels of FAP $\alpha$ were detected by doubleantibody sandwich ELISA, the specificity of the capture antibody and the detection antibody were validated by western blot analysis using recombinant human FAP $\alpha$ protein (Supplementary Figure 1A-1B). Figure 1A shows the plasma levels of FAP $\alpha$ in the healthy controls $(n=40)$ and the patients with diverse cancers $(n=212)$ respectively, which included liver cancer $(n=37)$, gastric cancer $(n=32)$, ESCC $(n=37)$, CRC $(n=38)$, nasopharyngeal cancer $(n=34)$, and lung cancer patients $(n=34)$ by ELISA. The mean plasma FAP $\alpha$ values from the ESCC patients $(57.55 \pm 23.48 \mathrm{ng} / \mathrm{ml}), \mathrm{CRC}$ patients $(52.09 \pm 24.63 \mathrm{ng} / \mathrm{ml})$ and liver cancer patients $(70.83 \pm 30.56 \mathrm{ng} / \mathrm{ml})$ were significantly lower than those from the healthy controls $(87.78 \pm 44.37 \mathrm{ng} / \mathrm{ml})(P=0.008 ; P=0.004$; $P=0.033$, Figure 1A). While the levels of FAP $\alpha$ in lung cancer patients, gastric cancer patients and nasopharyngeal cancer patients were similar to the healthy control. Extremely low levels of FAP $\alpha$ were found in the ESCC and $\mathrm{CRC}$ patient groups.

Furthermore, we expanded the cohort of ESCC patients $(n=151)$ and the benign ESCC $(n=36)$. As shown in Figure 1B, the FAP $\alpha$ levels of patients with benign esophageal disease were higher than those of patients with ESCC $(P=0.040)$ but similar to the healthy controls. The levels of FAP $\alpha$ in early-stage patients (stage I) were lower than those in healthy controls and higher than those in middle and late stage ESCC patients (stages II, III and IV), but showed no significant difference in either healthy controls or in middle and late stage ESCC (Figure 1B). Compared to the healthy controls, significant decline of FAP $\alpha$ levels were present from stage II to stages III and IV $(P<0.001$ and $P=0.008$; Figure 1B).

To further assess the levels of plasma FAP $\alpha$ before and after tumor resection, we collected plasma both preand post- operation $(n=20)$ and there was no significant difference between preoperative and postoperative FAP $\alpha$ levels.

\section{Diagnostic value of FAP $\alpha$ in ESCC patients}

The plasma FAP $\alpha$ level was able to distinguish ESCC patients $(n=151)$ from healthy controls $(n=194)$ and the benign ESCC $(n=36)$ with an AUC based on a ROC analysis (AUC $=0.714)$, whereas the AUCs of the traditional biomarkers of CEA, CYFRA211 and SCCA were $0.549,0.628$, and 0.653 , respectively (Figure 2A). The combination of FAP $\alpha$, CEA, CYFRA211 and SCCA resulted in an improvement in AUC (0.745) compared to the combination of the three traditional biomarkers $(\mathrm{AUC}=0.690)$ (Figure 2B).

However, as shown in Table 1, the sensitivity of FAP $\alpha$ was as high as $56.1 \%$, and the specificity reached $85.6 \%$ based on the optimal cut-off, and the sensitivity was $35.4 \%$ with the higher adjustment cutoff score $(38.6 \mathrm{ng} / \mathrm{ml})$ without compromising the specificity $(95.0 \%)$; Moreover, by combining with CEA, CYFRA211 and SCCA, the sensitivity and specificity reached $50.1 \%$ and $92.8 \%$ based on the optimal cut-off (0.548), and exhibited a higher sensitivity than combining the three traditional biomarkers alone $(32.9 \%)$. The findings validated that the effectiveness of plasma FAP $\alpha$ in the diagnosis of ESCC was higher than those of the traditional markers of CEA, CYFRA211 and SCCA.

\section{Association between plasma FAP $\alpha$ levels of ESCC and HDL-C}

The associations between the plasma FAP $\alpha$ levels and the clinicopathological parameters are presented in Table 2. The plasma FAP $\alpha$ levels were not associated with body mass index (BMI) and clinicopathological parameters including age, gender, T classification, lymph node metastasis, and clinical stage.

The associations of the plasma FAP $\alpha$ levels with the lipid profile and inflammatory biomarker C-reactive protein (CRP) were presented in Table 3. The plasma FAP $\alpha$ levels were not associated with TG, LDL-C, GLU, apoA1, apoB or CRP, but significantly associated with the HDL-C $(P<0.001)$. Moreover, a partial correlation analysis showed the positive correlation between plasma FAP $\alpha$ levels and HDL-C levels $(R=0.372, P<0.001$, Figure 3$)$.

The associations of the plasma FAP $\alpha$ levels with the coagulation indices were presented in Supplementary Table 1. The plasma FAP $\alpha$ levels were not associated with PT, PT\%, INR, APTT, FBG, TT, DD, FDP. These results indicated that coagulant activity and inflammation may have little effect on the plasma FAP $\alpha$ levels, but lipid profile level is correlated with plasma FAP $\alpha$ in the ESCC patients.

\section{Characterization of FAP $\alpha$ expression in ESCC tissues}

To evaluate FAP $\alpha$ expression in tumor tissues, we conducted immunohistochemistry with an antibody 
against human FAP $\alpha$ using prepared paraffin sections from pathological archives. The specificity of FAP $\alpha$ antibody was validated by western blot analysis (Supplementary Figure 1C). FAP $\alpha$ immunoreactivity was observed at varied levels in the stroma of ESCC tissues, but no FAP $\alpha$ immunostaining presented in epithelium of tumour tissues. The major localization was observed in the cytomembrane and/or cytoplasm of the surrounding stromal cells (Figure 4). FAP $\alpha$ was detected in 25 of the 27 ESCC samples $(94.6 \%)$, and strong expression was detected at 14 samples $(54.3 \%)$. This result indicated that FAP $\alpha$ was widely expressed in the stoma of ESCC tissues.

\section{FAP $\alpha$ was expressed and secreted in activated fibroblasts}

Studies have shown that transforming growth factorbeta (TGF $\beta$ ) is a potent inducer of fibroblast activation in a variety of cancers [19-21]. In order to identify whether FAP $\alpha$ can express and secrete in activated fibroblasts, qRT-PCR and Western blotting were performed in fibroblast cell lines, 3T3 and L929 with the treatment of TGF $\beta 1$. FAP $\alpha$ mRNA and protein were hardly detected in 3T3 and L929 cell lines, but increased significantly in both 3 T3 and L929 cells after incubated with TGF $\beta$ for $48 \mathrm{~h}$ (Figure 5A-5B), whiles 3T3 and L929 cell lines treated with culture supernatant form Eca-109, or co-cultured with Eca-109 cells did not express FAP $\alpha$. This result exposed that FAP $\alpha$ was expressed in activated fibroblasts but not expressed in normal fibroblasts or tumor cells.

To clarify why FAP $\alpha$ was strongly expressed in
CAFs in most of ESCC tissues but was distinctly low in ESCC patients' blood, ELISA and immunoprecipitation were used to test if FAP $\alpha$ can secrete into the culture supernatant. Soluble FAP $\alpha$ was unable to detect directly in supernatant, no matter TGF $\beta$ was added or not (Figure 5C). In contrast, high FAP $\alpha$ expression was detected in the cell lysate when incubated with TGF $\beta$. Furthermore, $8 \mathrm{~mL}$ cells supernatant of 3T3 and L929 cells which treated by TGF $\beta$ was collected and lyophilized. Then, FAP $\alpha$ was detected in the concentrated supernatant by immunoprecipitation. As shown in Figure 5D, FAP $\alpha$ was detected in highly concentrated supernatant of both 3T3 and L929 cells by a Long exposure time of Western blot analysis. These results confirmed that FAP $\alpha$ was expressed with extremely low concentrations in the cell supernatant of activated fibroblasts, and suggested that activated fibroblasts have limited capacity to secrete soluble FAP $\alpha$.

\section{The soluble FAP $\alpha$ originated from tumor and other normal tissues}

Next, we wanted to find out where the plasma FAP $\alpha$ came from. We collected plasma both pre- and postinjection of xenograft $(n=6)$ and there was no significant difference between the FAP $\alpha$ levels, although Eca-109 xenograft tissues showed the strong positive expression of FAP $\alpha$ in stromal cell (Figure 6A).

As shown in Figure 6, the FAP $\alpha$ expression was very low in tumor because only the CAFs expressed FAP $\alpha$ but tumor cells didn't when the tumor consisted of most the tumor cells (Figure 6A). In addition, compared to the

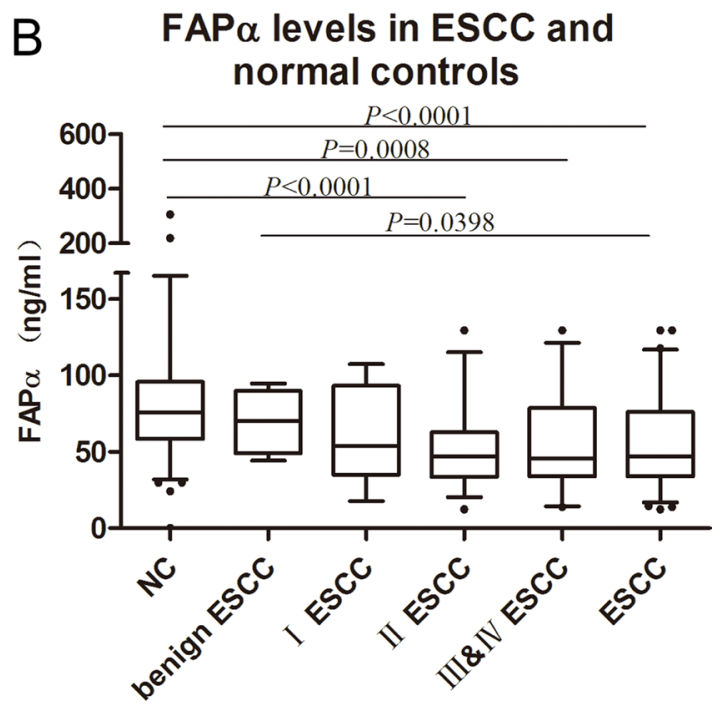

Figure 1: FAPa levels detected in the plasma of ESCC patients. (A) Significant decline were found in the comparison between normal controls $(87.78,95 \% \mathrm{Cl}: 73.40-102.2)$ and $\operatorname{ESCC}(57.55,95 \% \mathrm{Cl}: 49.72-65.38)$, HCC (64.56, 95\% Cl: 52.86-76.27), CRC(52.09, 95\% Cl: 41.92-62.25) patients. (B) Plasma FAP $\alpha$ comparison between healthy controls (80.67, 95\% Cl: 72.49-88.86), benign ESCC (70.01, 95\% Cl: 55.74-84.28), I ESCC (61.45, 95\% Cl: 44.31-78.59), II ESCC (51.80, 95\% Cl: 42.51-61.09), III \& IV ESCC (55.56, 95\% $\mathrm{Cl}$ : 44.22-66.90) and $\operatorname{ESCC}(56.79,95 \% \mathrm{Cl}$ : 49.59-64.00). "NC" is short for "normal control". "CRC" is short for "colorectal cancer". "LC" is short for "lung cancer". "NPC" is short for "nasopharyngeal carcinoma". "HCC" is short for "hepatocellular carcinoma". "GC" is short for "gastric cancer". 

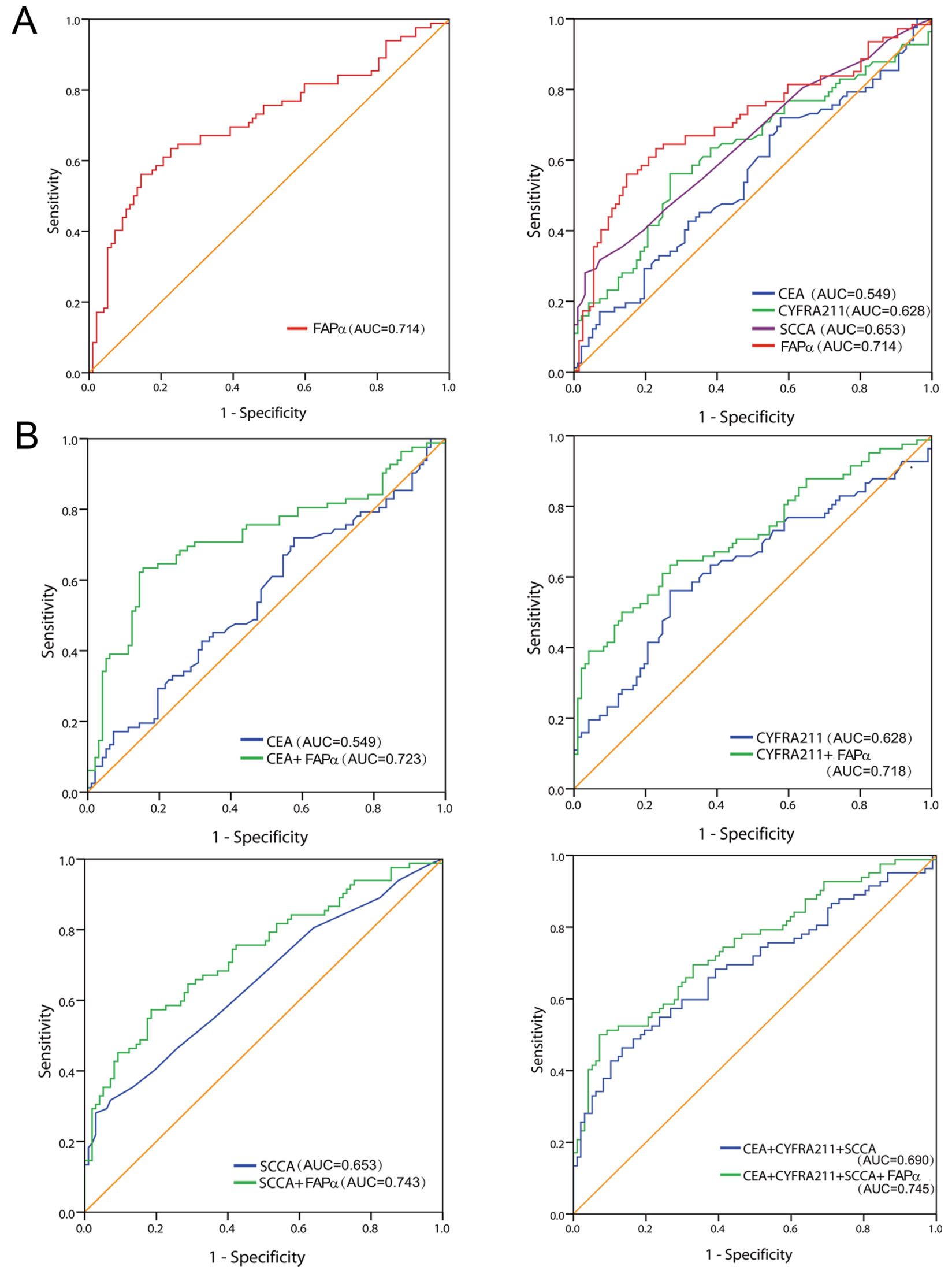

Figure 2: Diagnostic value of plasma FAP $\alpha$ in ESCC patients. (A) The ROC curves demonstrated the diagnostic strength of FAP $\alpha$, CEA, CYFR211, SCCA. (B) The combined ROC curves of plasma FAP $\alpha$, CEA, CYFR211, SCCA respectively and the combination of four of them in diagnosis of ESCC against former controls. 
Table 1: Diagnostic values of seprase and traditional biomarker

\begin{tabular}{lccc}
\hline combinations & Cut off & Sensitivity (\%) & Specificity (\%) \\
\hline seprase & 49.035 & 56.1 & 85.6 \\
CEA & 38.575 & 35.4 & 95.0 \\
& 1.895 & 72.0 & 42.3 \\
CYFRA211 & 5.29 & 12.2 & 95.0 \\
SCCA & 3.035 & 56.1 & 73.2 \\
& 4.930 & 19.5 & 95.0 \\
CEA+ seprase & 1.600 & 28.0 & 96.9 \\
& 1.45 & 29.3 & 94.0 \\
CYFRA211+ seprase & 0.516 & 63.4 & 84.5 \\
& 0.578 & 37.8 & 95.0 \\
SCCA + seprase & 0.461 & 63.4 & 73.2 \\
& 0.588 & 39.0 & 95.0 \\
CEA+CYFRA211+SCCA & 0.478 & 57.3 & 81.4 \\
& 0.603 & 35.4 & 95.0 \\
CEA+CYFRA211+SCCA+ seprase & 0.478 & 46.3 & 86.6 \\
& 0.594 & 32.9 & 95.0 \\
\hline
\end{tabular}

Table 2: Clinical characteristics and seprase levels of the ESCC patients

\begin{tabular}{|c|c|c|c|}
\hline \multirow{2}{*}{ characteristics } & \multirow{2}{*}{ Case numbers } & \multicolumn{2}{|c|}{ seprase $(\mathrm{ng} / \mathrm{ml})$} \\
\hline & & Median(range) & $P$ Value \\
\hline \multicolumn{4}{|l|}{ BMI } \\
\hline$<18.5$ & 28 & $50.88(12.43-117.75)$ & 0.860 \\
\hline $18.5-25$ & 103 & $58.95(13.85-187.43)$ & \\
\hline$>25$ & 20 & $63.50(27.69-106.22)$ & \\
\hline Age, years & & & 0.343 \\
\hline$<=62$ & 77 & $54.36(12.43-141.57)$ & \\
\hline$>62$ & 74 & $61.47(13.85-187.43)$ & \\
\hline Gender & & & 0.152 \\
\hline Male & 114 & $54.79(12.43-187.43)$ & \\
\hline Female & 37 & $67.24(29.58-141.57)$ & \\
\hline pT status & & & 0.054 \\
\hline pT1 & 33 & $67.75(17.70-141.57)$ & \\
\hline pT2 & 32 & $48.45(24.44-99.15)$ & \\
\hline pT3 & 77 & $53.76(12.43-187.43)$ & \\
\hline pT4 & 9 & $88.16(41.87-129.57)$ & \\
\hline pN status & & & 0.880 \\
\hline pNo & 79 & $57.29(12.43-141.57)$ & \\
\hline pN1-3 & 72 & $58.42(13.85-187.43)$ & \\
\hline pTNM status & & & 0.346 \\
\hline Stage I & 29 & $66.46(17.70-141.75)$ & \\
\hline Stage II & 59 & $51.80(12.43-129.57)$ & \\
\hline Stage III \& IV & 63 & $59.44(13.85-187.43)$ & \\
\hline
\end{tabular}


Table 3: Expression of seprase with different characteristics of biochemical parameters

\begin{tabular}{|c|c|c|c|c|}
\hline \multirow{2}{*}{\multicolumn{2}{|c|}{ characteristics }} & \multirow{2}{*}{ Case numbers } & \multicolumn{2}{|c|}{ seprase (ng/ml) } \\
\hline & & & Median(range) & $P$ Value \\
\hline \multirow{2}{*}{ CRP } & $0-8.2$ & 120 & $60.29(13.85-141.57)$ & 0.198 \\
\hline & $>8.2$ & 31 & $48.40(12.43-187.43)$ & \\
\hline \multirow{2}{*}{$\mathrm{CHO}$} & $1.2-6.47$ & 139 & $56.40(12.43-187.43)$ & 0.175 \\
\hline & $>6.47$ & 12 & $75.87(28.17-117.75)$ & \\
\hline \multirow{2}{*}{ TG } & $0.2-1.7$ & 127 & $56.34(12.43-187.43)$ & 0.360 \\
\hline & $>1.7$ & 24 & $65.72(27.88-141.57)$ & \\
\hline \multirow[t]{3}{*}{ HDL } & $<0.78$ & 7 & $39.69(12.43-69.17)$ & $<0.001$ \\
\hline & $0.78-2.20$ & 143 & $57.09(13.85-141.57)$ & \\
\hline & $>2.20$ & 1 & 187.43 & \\
\hline \multirow[t]{3}{*}{ LDL } & $<2.2$ & 15 & $45.33(12.43-73.05)$ & 0.222 \\
\hline & $2.2-3.4$ & 85 & $55.07(13.85-141.57)$ & \\
\hline & $>3.4$ & 51 & $65.93(16.86-187.43)$ & \\
\hline \multirow[t]{3}{*}{ APOA1 } & $<1.05$ & 31 & $58.66(12.43-141.57)$ & 0.991 \\
\hline & $1.05-1.76$ & 116 & $57.67(13.85-187.43)$ & \\
\hline & $>1.76$ & 4 & $55.82(43.51-68.12)$ & \\
\hline \multirow[t]{3}{*}{ APOB } & $<0.63$ & 4 & $40.28(12.43-68.12)$ & 0.309 \\
\hline & $0.63-1.14$ & 118 & $55.72(13.85-141.57)$ & \\
\hline & $>1.14$ & 29 & $68.43(16.86-187.43)$ & \\
\hline
\end{tabular}

tumor tissues, expression of FAP $\alpha$ in bone marrow, liver and skeletal muscle tissues was significantly higher, which disclosed that FAP $\alpha$ were expressed in multiple normal tissues other than only in tumors, and FAP $\alpha^{+}$stromal cells in multiple normal tissues might be the physiologic source of the FAP $\alpha$. Furthermore, Western blotting and qRT-PCR were performed in the Eca-109 xenograft tumor, liver and skeletal muscle tissue homogenate.

\section{DISCUSSION}

In this study, the plasma FAP $\alpha$ levels were found to be significantly reduced in the ESCC patients compared to healthy controls. This was a contradictory conclusion according to extensive evidence showing that high expression of FAP $\alpha$ in tumor tissue [22-26]. Consistent with the finding of this study, multiple reports have showed that plasma FAP $\alpha$ levels were lower in cancer patients compared with healthy volunteers [4, 8, 27],

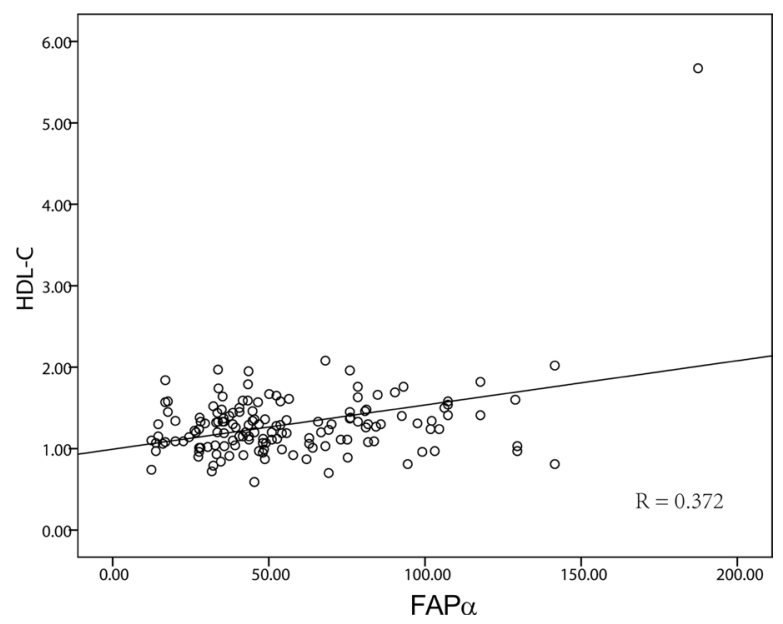

Figure 3: The correlation of FAP $\alpha$ and HDL. The expression level of FAP $\alpha$ and HDL-C were significantly positively correlated $(P<0.001, R=0.372)$. 

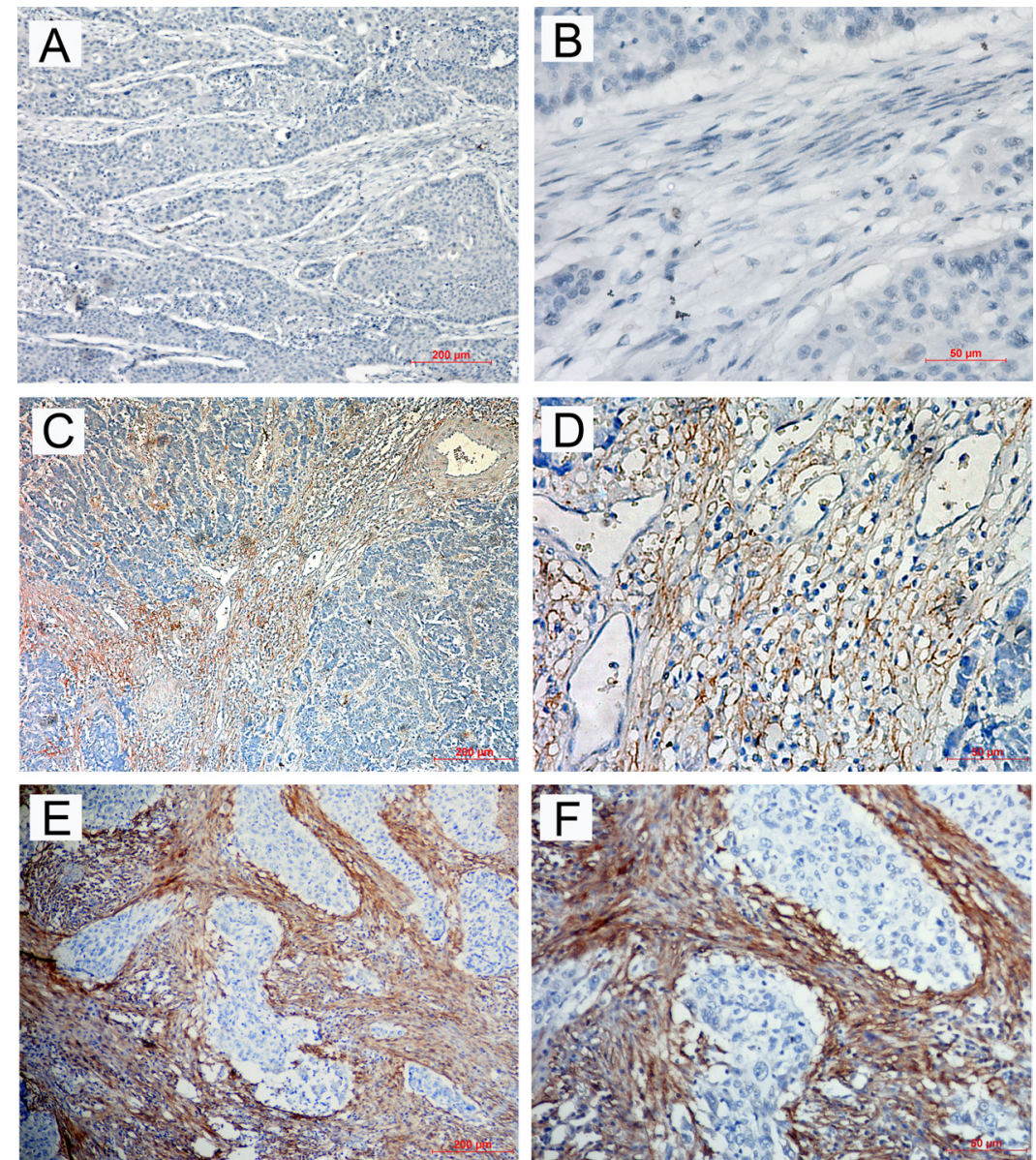

Figure 4: Immunohistochemical staining for FAP $\alpha$ in ESCC tissues. The negative expression level $(\mathbf{A}) \times 100 ;(\mathbf{B}) \times 400)$, low expression level $(\mathbf{C}) \times 100 ;(\mathbf{D}) \times 400)$ and high expression level $(\mathbf{E}) \times 100 ;(\mathbf{F}) \times 400)$ of FAP $\alpha$ in ESCC patients.
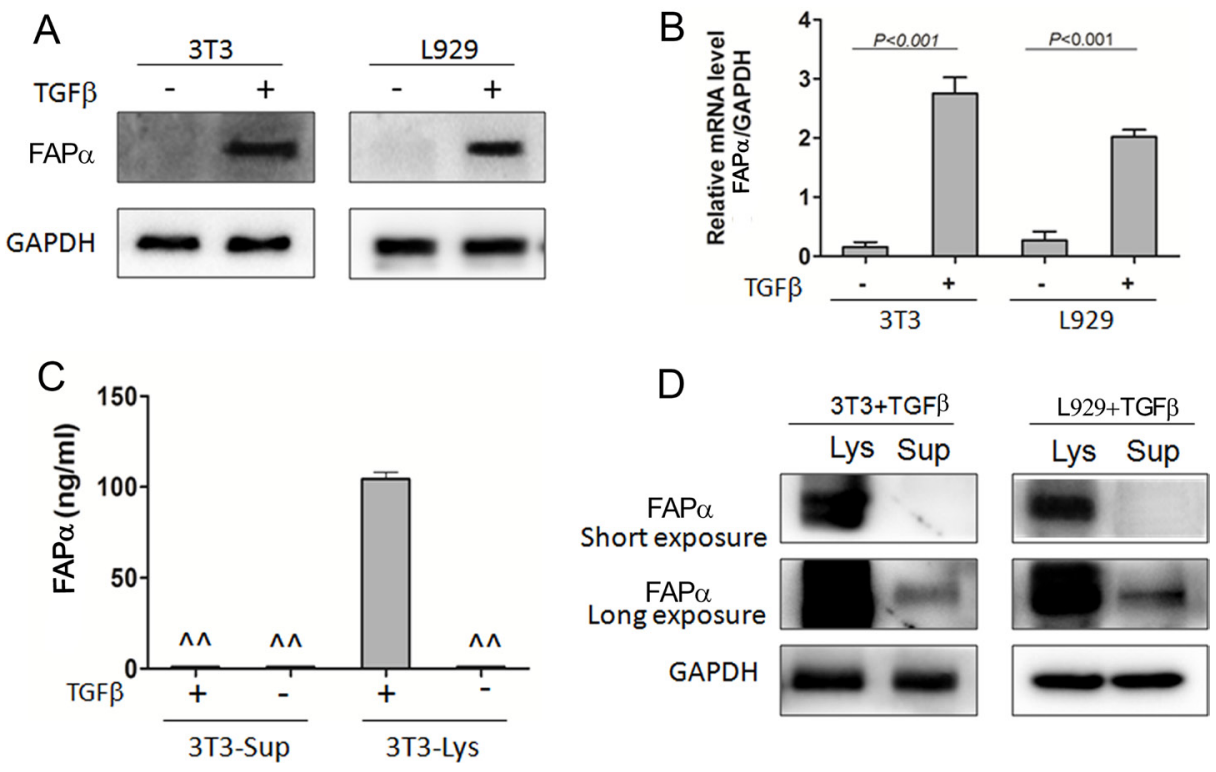

Figure 5: Soluble FAP $\alpha$ detected in the cell supernatant and lysate of fibroblast cell lines. (A, B) FAP $\alpha$ protein and mRNA expression detected by western blot and qPCR in the fibroblast cells, 3T3 and L929. TGF $3(20 \mathrm{ng} / \mathrm{ml})$ was incubated with fibroblast cells for 48 h. (C) FAP $\alpha$ e expression detected by ELISA. “^^” means the expression is below the detection limit. (D) FAP $\alpha$ expression detected by Immunoprecipitation in the fibroblast cells. 
and decline level of circulating FAP $\alpha$ even presented in pancreatic ductal adenocarcinoma which drives formation of the fibroblast-rich desmoplastic stroma [22].

FAP $\alpha$, as a member of the dipeptidyl prolyl peptidase (DPP) family, has been reported to be a competent diagnostic and therapeutic target because of its high expression in solid tumors and its potential function in tumor invasion [28-31]. In this study, we confirmed that FAP $\alpha$ was overexpressed in human ESCC tissues; This result detected in tumor tissues was contrary to the result detected in the plasma of ESCC patients. In addition, we compared the plasma FAP $\alpha$ level before and after tumor resection and found not significant difference between them. Furthermore, low mouse plasma FAP $\alpha$ levels show inconsistent results with the high expression of FAP $\alpha$ in xenograft tumors tissues, and plasma FAP $\alpha$ levels did not increase along with the tumor growth in our study, which was in line with the result that plasma FAP $\alpha$ had no correlation with the clinicopathological parameters of ESCC patients. Those findings indicated that the FAP $\alpha$ from tumor is not the major contributor to the circulating FAP $\alpha$.

$F A P \alpha$ showed immunosuppressive functions in a tumor microenvironment, and depletion of FAP $\alpha$ in stromal cells suppressed the growth of solid malignant tumors [32]. FAP $\alpha$ was reported to be expressed on activated fibroblasts specifically, and could be induced by the important immunosuppressive factor: TGF $\beta$ [33]. We examined the expression of FAP $\alpha$ in fibroblasts, and identified that FAP $\alpha$ was induced by the TGF $\beta$. Moreover,
FAP $\alpha$ is an integral membrane protein and lacks a secretory signal peptide [34]. Consistently, our study demonstrated soluble form of FAP $\alpha$ in the supernatant of activated fibroblasts was very limited by immunoprecipitation assay. In addition, FAP $\alpha$ was shed from cells as soluble forms in vitro, and showed further activation of its proteolytic activity through metalloprotease-mediated truncation [35]. We further examined the expression of FAP $\alpha$ of fibroblasts treated with the supernatant of Eca-109 tumor cells, but no FAP $\alpha$ expression was detected in fibroblasts. Those results confirmed that the $\mathrm{FAP} \alpha$ expressed in tumor hardly secreted into the interstitial space or secrete into the plasma, and further showed the circulating FAP $\alpha$ was independent of the tumor.

Although soluble FAP $\alpha$ has also been identified in blood [36-37], the origin of circulating FAP $\alpha$ has not been elucidated. Circulating FAP $\alpha$ is previously speculated to derive from two distinct sources in cancer patients: yet-to-be-identified physiologic source(s), and the tumor [8]. Recently, there is evidence suggesting that the hepatobiliary system and immune cells are the primary physiologic sources of circulating FAP $\alpha$. In our study, FAP $\alpha$ was present in a wide range of normal tissues, including liver, skeletal muscle and bone marrow in the human xenograft mouse model. Our data is consistent with the study in which plasma soluble FAP $\alpha(\operatorname{sFAP} \alpha)$ levels were increased in patients with liver cirrhosis [38]. Though the expression level of FAP $\alpha$ was a little low in normal tissues such as bone marrow, the multi-organ contributed
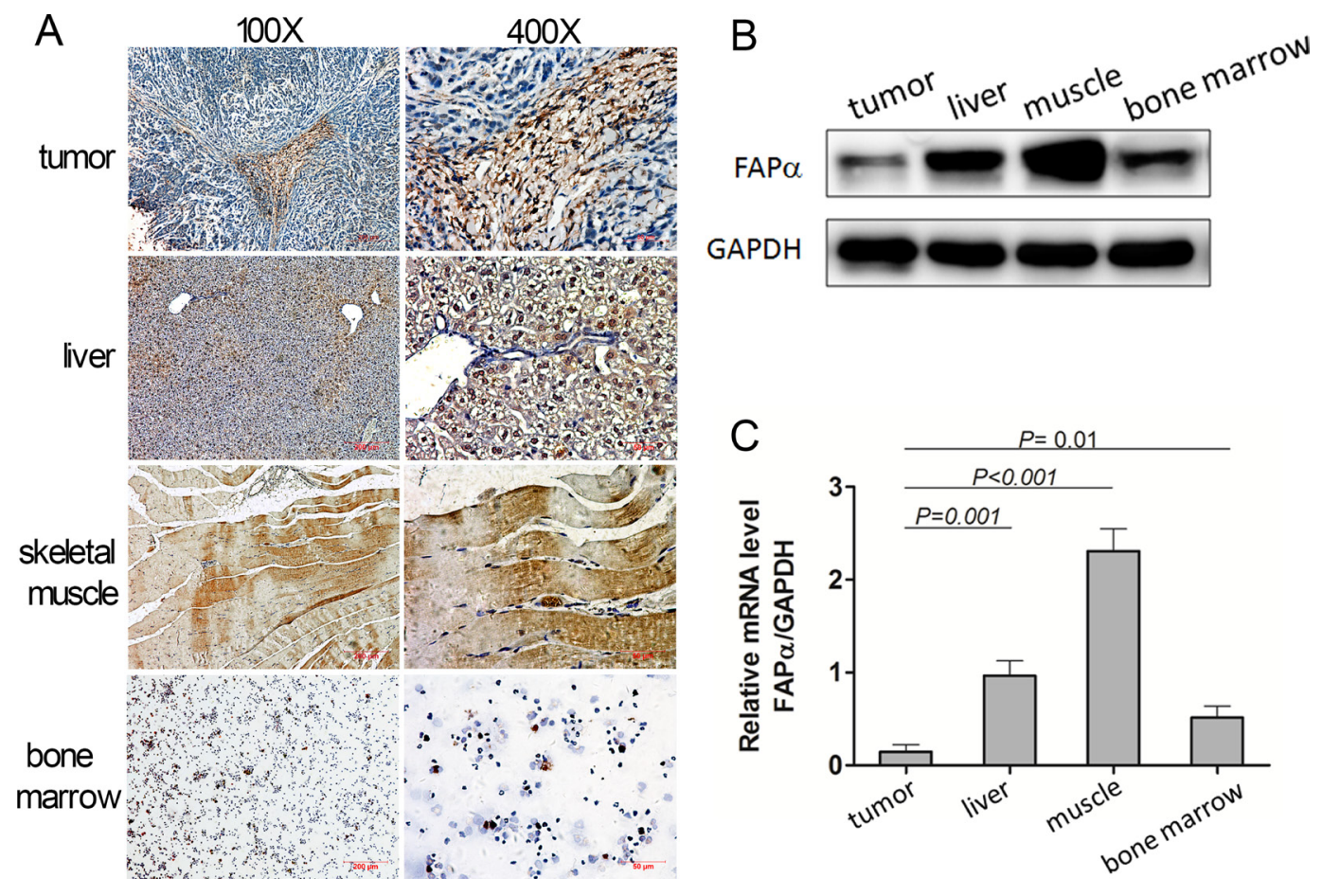

Figure 6: Expression of FAP $\alpha$ detected in the mouse tumor, normal tissues and mouse plasma. (A) Immunohistochemical staining for FAP $\alpha$ in mouse tumor and normal tissues. (B, C) FAP $\alpha$ protein and mRNA expression detected by western blot and qPCR in the mouse tumor, mouse liver and mouse muscle. 
to the high circulating levels of FAP $\alpha$ in healthy individuals. Furthermore, the expression in the muscles was significantly higher than the others. This result exposed that compared to the FAP $\alpha$ expressed in liver and muscle, the FAP $\alpha$ expressed in tumor was negligible. Liver and muscle, especially the muscle, might be the physiologic source of the FAP $\alpha$. Our results indicated the circulating FAP $\alpha$ was more influenced by the physiologic source than the FAP which expressed in tumor.

Interestingly, the APCE, which circulates in blood and appears structurally similar to $\mathrm{FAP} \alpha$, was identified as a truncated, soluble form of FAP $\alpha$ [36]. Moreover, fibrinolysis inhibitor $\alpha 2$-antiplasmin ( $\alpha 2 \mathrm{AP}$ ) has been described as a potential in vivo substrate of $\operatorname{sFAP} \alpha$. In addition, soluble FAP $\alpha$ levels were reported to reduce in the coronary heart disease (CHD) patient population, but only in the first months after the event, indicating that sFAP $\alpha$ levels may normalize over time [39]. These results indicated that coagulant activity might be compensated for the change of FAP $\alpha$ levels in blood. In our study, however, the plasma FAP $\alpha$ levels were not associated with hemostasis indices. Was it because sFAP $\alpha$ levels change over time? The reason remains to be further explored.

In cancer, lipid and cholesterol homeostasis are often dysregulated to facilitate the cancer cells' increased demand for these building blocks which are required for proliferation and evasion of apoptosis. Interestingly, our data showed that plasma FAP $\alpha$ was positive correlated $(\mathrm{R}=0.372)$ with HDL-C level in the ESCC patients, but showed no correlation with apoA-I (the major protein component of HDL). Recently, HDL-C levels have reported to be significantly lower in ESCC patients than in normal controls [40]. Low HDL-C level was found to be a risky and prognostic factor of multiple cancers in several epidemiologic studies [41]. Hence, similar with the HDL-C, the lower level of plasma FAP $\alpha$ in cancer patients could possibly be a phenomenon comparable to decreased plasma level of acute-phase proteins discovered in inflammatory processes and malignancy (e.g., low plasma levels of transferrin, albumin, and inter-alphatrypsin inhibitors) [8], or related to other speculated processes, such as the organ function decline and muscle mass consumption, which indicated the plasma FAP $\alpha$ was a negative acute-phase protein in response to tumor.

Currently, CEA, SCCA and CYFRA211 are the three most commonly used diagnosis markers for ESCC. However, serum tests of the three markers have poor sensitivity. In our study, FAP $\alpha$ showed good sensitivity (56.1\%) and specificity $(85.6 \%)$ in diagnosis of ESCC, and exhibited much higher sensitivity (35.4\%) than CEA (12.2\%), SCCA (29.3\%) and CYFRA211 (19.5\%) without compromising specificity (95.0\%). Moreover, FAP $\alpha$ combined with the three traditional biomarkers improved the sensitivity (41.5\%) without compromising specificity $(95.0 \%)$ for ESCC detection. Our data were consistent with those studies in which FAP $\alpha$ improved the diagnostic value of CRC [4-5].
These results showd the screen value of FAP $\alpha$ for ESCC, and demonstrated that the combination of FAP $\alpha$ and the three traditional biomarkers can detect about $40 \%$ ESCC.

In summary, FAP $\alpha$ is expressed not only in tumors tissues, but also in multiple normal tissues, and FAP $\alpha^{+}$ cells have very limited ability to secrete soluble FAP $\alpha$. So circulating FAP $\alpha$ source may come from multiple normal tissues, and lower levels of plasma FAP $\alpha$ in ESCC may be a systemic reaction to the presence of tumor. Furthermore, we found out plasma FAP $\alpha$ can screen ESCC and improve the diagnosis of ESCC by combined with other traditional biomarkers, indicating that circulating FAP $\alpha$ was a potential indicator for the diagnosis of ESCC.

\section{MATERIALS AND METHODS}

\section{Patients, blood and tissue samples}

Plasma was obtained from 326 patients at Sun Yat-Sen University Cancer Center from July 2015 to June 2016, which consisted of liver cancer $(n=37$, gastric cancer $(n=32), \operatorname{ESCC}(\mathrm{n}=151), \operatorname{CRC}(n=38)$, nasopharyngeal cancer $(n=34)$, and lung cancer patients $(n=34)$. All cancers were diagnosed based upon the histopathology examination.

The cohort of ESCC patients was consisted of 114 male patients and 37 female patients. The patients ranged in age from 45 to 79 years (mean, 62 years); none had received radiotherapy or chemotherapy prior to surgery. Patients with inflammatory diseases were excluded. 20 paired plasma samples were collected from ESCC patients before tumor resection and 5-7 days post-resection. All plasmas from patients with tumors were collected at the Cancer Center of Sun Yat-sen University at the time of diagnosis and prior to tumor radiation therapy or surgery. The 151 patient characteristics are described in Table 1.

Plasma from 36 patients with benign esophageal disease (21 cases of reflux esophagitis, 6 cases of acute suppurative esophagitis and 9 cases of esophageal hiatal hernia), and plasma from 194 healthy volunteers (144 males, 50 females) without inflammation (ages 36-77 years, mean $=59$ years) were collected from Guangzhou First Municipal People's Hospital from July 2015 to June 2016. Healthy controls samples were matched as closely as possible to the ESCC group with respect to previous handling and the time period of sample collection.

Paraffin-embedded tumour tissue samples were obtained from 34 ESCC patients underwent surgery between May of 2000 and December of 2002. None of the patients had received anticancer treatment prior to surgery, and all of the patients had been histologically confirmed primary ESCC in this retrospective study. The pTNM classification was applied according to guidelines from the 2009 UICC/AJCC Tumor-Node-Metastasis (TNM) classification system. [42].

All plasma samples were stored at $-80^{\circ} \mathrm{C}$ and were 
measured in 3 months. Each clotted sample was centrifuged at $1,500 \mathrm{~g}$ for $10 \mathrm{~min}$. The study was approved by the Ethics Committee of Sun Yat-sen University Cancer Center and Ethics Committee of Guangzhou First Municipal People's Hospital, informed consent was obtained from each patient.

\section{Cell lines}

The human ESCC cell lines Eca-109, mouse fibroblast cell line NIH 3T3 and L929 (Chinese Academy of Sciences, Shanghai, China) were grown in RPMI 1640 (Invitrogen, USA) supplemented with 10\% fetal bovine serum. NIH/3T3 and L929 fibroblasts cells were characterized by the expression of myofibroblasts markers: $\alpha$-smooth muscle actin ( $\alpha$-SMA) with TGF- $\beta 1$ treatment (Supplementary Figure 2).

\section{Xenograft tumor tissues}

The six- to eight-week-old BALB/c-nude mice were provided by Guangdong Medical Laboratory Animal Centre (Guangdong, China) and housed under specific pathogen free conditions in the Laboratory Animal Center of Sun Yat-sen University. This study was approved by the ethics committee of Sun Yat-Sen University. The mice were inoculated subcutaneously under the right shoulder with $2 \times 10^{6}$ Eca109 cells. Plasma samples were collected prior to first inoculation and every week after inoculation. After growing for 5 weeks, the animals were sacrificed, and the xenograft tumors, livers and the muscles were removed for use.

\section{ELISA assay of FAP $\alpha$}

Human plasma FAP $\alpha$ levels were determined by double-antibody sandwich ELISA according to the manufacturer's instructions (Human FAP DuoSet ELISA, DY3715, R\&D systems, USA). Briefly, 96-well microplates were coated with $100 \mu \mathrm{l} /$ well of the capture antibody (mouse anti-human FAP $\alpha$ antibody, $1 \mu \mathrm{g} / \mathrm{ml}$, MAB3715) overnight at room temperature and washed thrice with PBS containing 0.05\% Tween-20. After blocking with $1 \% \mathrm{BSA}$ for $1 \mathrm{~h}$ at room temperature and another washing step, $100 \mu \mathrm{l}$ of the test samples (1:50 diluted in 1\% BSA) was added and incubated for $2 \mathrm{~h}$ at room temperature. Subsequently, after the washing step, $100 \mu \mathrm{l} /$ well of the detection antibody (biotinylated sheep anti-human FAP $\alpha$ antibody, $200 \mathrm{ng} / \mathrm{ml}$, BAF3715) was added and incubated for $2 \mathrm{~h}$ at room temperature. After the washing step, $100 \mu \mathrm{l} /$ well of Streptavidin-HRP (1:200) was added and incubated for $20 \mathrm{~min}$ at room temperature. Washing thrice again and finally, the substrate (tetramethylbenzidine) solution was added $100 \mu \mathrm{l} /$ well, and the reaction was terminated using $2 \mathrm{~N} \mathrm{H}_{2} \mathrm{SO}_{4}$ and read at an OD of $450 \mathrm{~nm}$. S32 SsSSSsSamples and standards were measured in duplicate. In each experiment, a seven point standard curve was generated using 2-fold serial dilutions of rhFAP from $4,000 \mathrm{pg} / \mathrm{mL}$ to $62.5 \mathrm{pg} / \mathrm{mL}$ in reagent diluent and a four parameter logistic curvefit for each ELISA plate was constructed to calculate corresponding FAP $\alpha$ concentrations in individual samples. Each test included a standard control $(\mathrm{CV}=12 \%)$. The operator performing the ELISA was blinded regarding the patient characteristics of samples analyzed.

Mouse plasma and soluble FAP $\alpha$ of mouse fibroblast cell line were determined by double-antibody sandwich ELISA using Mouse FAP ELISA kit (CUSABIO, China, CSB-EL008424MO) according to the manufacturer's instructions.

\section{Tumor markers, biochemical and hemostasis indices assay}

The concentrations of CEA and CYFRA211 in the plasma were assessed using electrochemiluminescence immunoassay (ECLIA) kits (Roche, Germany) on a Roche E170 fully automatic electrochemistry luminescence immunity analyzer (Roche, German). The levels of SCCA in the plasma were detected using an ARCHITECT I2000SR immune analyze system (Abbott, America). Each test included a standard control $(\mathrm{CV}<5 \%)$.

The plasma biochemical indices including $\mathrm{TG}$, CHO, HDL-C, LDL-C(WAKO, Japan), ApoA1, Apo$\mathrm{B}$ (Maccura,China) and inflammatory biomarker CRP (WAKO, Japan) were measured on an automatic biochemical analyzer (LABOSPECT 008; Hitachi HighTechnologies Corporation, Japan).

The plasma hemostasis indices including PT, APTT, FBG, TT, DD (Siemens, Germany) and FDP (BIOLINKS CO., LTD, Japan) were measured on an automatic coagulation analyzer (SYSMEX CS-5100 Hemostasis System, Japan). PT\% and INR were calculated according to the formula recommended by the manufacture's instruction.

\section{RNA extraction and real-time quantitative PCR}

Total RNA was extracted from cell lines using the Trizol reagent (Invitrogen, USA) according to the manufacture's instruction. Reverse transcription of total RNA (800 ng) was done using SuperScript II reverse transcriptase. The quantification of target and reference gene (GAPDH) were performed in triplicate on a LightCycler $^{\circledR} 480$ II (Roche, Applied Science) using a SYBR green-based assay (BioRad, USA). Expression data were normalized to the geometric mean by housekeeping gene GAPDH as an internal control. The primers used in the real-time RT-PCR reaction were as follows: FAP $\alpha$, 5'-ATCTATGACCTTAGCAATGGAGAATTTGT-3' (forward), 5'-GTTTTGATAGACATATGCTAATTTACT CCCAAC-3' (reverse); and GAPDH, 5'-GACTCATGACC ACAGTCCATGC-3' (forward) and 5'-AGAGGCAGGGA TGATGTTCTG-3' (reverse). 


\section{Immunoprecipitation (IP)}

After the lyophilization of cells supernatant, PBS was used to dissolve the powder. Then FAP $\alpha$ antibody (1:40, AF3715, R\&D, USA) was added in the PBS buffer and shaked at $4^{\circ} \mathrm{C}$ overnight. Protein $\mathrm{A}+\mathrm{G}$ Agarose (Beyotime Biotechnology, China) was added for $4 \mathrm{~h}$ and then centrifuged at $1000 \mathrm{~g}, 5 \mathrm{~min}$ for 5 times. Next, equivalent protein amounts were denatured in an SDS sample buffer and were ready for the Western blot analysis.

\section{Western blot analysis}

Total protein was extracted using a lysis buffer and protease inhibitor (Beyotime Biotechnology, China). Equivalent protein amounts were denatured in an SDS sample buffer, and then were separated by SDS-PAGE and transferred onto polyvinylidene difluoride membrane. After being blocked with 5\% non-fat dry milk in PBS containing $0.05 \%$ Tween-20, the blotted membranes were incubated with anti-human FAP $\alpha$ antibody (1:2000, AF3715, R\&D, USA) and secondary antibody (1:5000, Boster, China) thereafter. GAPDH protein levels were also determined by using the specific antibody (1:1000, Boster, China) as a loading control.

\section{Immunohistochemistry}

The paraffin-embedded tissues were sectioned into $4-\mu \mathrm{m}$-thick sections. The sections were dewaxed, rehydrated and rinsed. The antigens were retrieved by heating the tissue sections at $100^{\circ} \mathrm{C}$ for $20 \mathrm{~min}$ in citrate $(10 \mathrm{mmol} / \mathrm{L}, \mathrm{pH}$ 6.0) solution when necessary. The sections were subsequently immersed in a $3 \%$ hydrogen peroxide solution for 10 min to block endogenous peroxidase activity and were incubated with the primary antibody sheep anti-human FAP (1:200, AF3715, R\&D, USA) at $4^{\circ} \mathrm{C}$ overnight. A negative control was performed by replacing the primary antibody with PBS. The sections were then incubated with a horseradish peroxidase labeled secondary antibody (1:100, Boster, China) at room temperature for $120 \mathrm{~min}$. Finally, the signal was developed for visualization with 3, 3'-diaminobenzidine tetrahydrochloride, and all of the slides were counterstained with hematoxylin.

\section{Statistical analysis}

All statistical analyses were carried out using the SPSS 16.0 statistical software package (SPSS Inc., Chicago, IL, USA). The Mann-Whitney U test was used to evaluate the difference in plasma FAP $\alpha$, concentrations between tumor patients and healthy controls. Pearson>s chi-squared test was used to analyze the relationship between FAP $\alpha$ levels and patients' clinical parameters' characteristics. The efficacy of diagnosis for ESCC was evaluated by the area under receiver operating characteristic (ROC) curve (AUC). The cut-off values were defined as the value either with the maximization of the Yuden index or the $90 \%$ specificity. Furthermore, sensitivity, specificity were used to compare the efficiency of diagnosis. All statistical tests were two-side, $P<0.05$ was considered to be statistically significant in all cases.

\section{ACKNOWLEDGMENTS AND FUNDING}

This work was supported by the National Natural Science Foundation of China (No. 81372573).

\section{CONFLICTS OF INTEREST}

The authors declare no conflicts of interest.

\section{REFERENCES}

1. Enzinger PC, Mayer RJ. Esophageal cancer. N Engl J Med. 2003; 349:2241-52.

2. Aghcheli K, Marjani HA, Nasrollahzadeh D, Islami F, Shakeri R, Sotoudeh M, Abedi-Ardekani B, Ghavamnasiri MR, Razaei E, Khalilipour E, Mohtashami S, Makhdoomi Y, Rajabzadeh R, et al. Prognostic factors for esophageal squamous cell carcinoma--a population-based study in Golestan Province, Iran, a high incidence area. PLoS One. 2011; 6:e22152.

3. Zheng X, Xing S, Liu XM, Liu W, Liu D, Chi PD, Chen H, Dai SQ, Zhong Q, Zeng MS1, Liu WL. Establishment of using serum YKL-40 and SCCA in combination for the diagnosis of patients with esophageal squamous cell carcinoma. BMC Cancer. 2014; 14:490.

4. Wild N, Andres H, Rollinger W, Krause F, Dilba P, Tacke M, Karl J. A combination of serum markers for the early detection of colorectal cancer. Clin Cancer Res. 2010; 16:6111-21.

5. Werner S, Krause F, Rolny V, Strobl M, Morgenstern D, Datz C, Chen H, Brenner H. Evaluation of a 5-Marker Blood Test for Colorectal Cancer Early Detection in a Colorectal Cancer Screening Setting. Clin Cancer Res. 2016; 22:1725-33.

6. Scherz-Shouval R, Santagata S, Mendillo ML, Sholl LM, Ben-Aharon I, Beck AH, Dias-Santagata D, Koeva M, Stemmer SM, Whitesell L, Lindquist S. The reprogramming of tumor stroma by HSF1 is a potent enabler of malignancy. Cell. 2014; 158:564-78.

7. Hanahan D, Weinberg RA. Hallmarks of cancer: the next generation. Cell. 2011; 144:646-74.

8. Javidroozi M, Zucker S, Chen WT. Plasma seprase and DPP4 levels as markers of disease and prognosis in cancer. Dis Markers. 2012; 32:309-20.

9. Busek P, Vanickova Z, Hrabal P, Brabec M, Fric P, Zavoral M, Skrha J, Kmochova K, Laclav M, Bunganic B, 
Augustyns K, Van Der Veken P, Sedo A. Increased tissue and circulating levels of dipeptidyl peptidase-IV enzymatic activity in patients with pancreatic ductal adenocarcinoma. Pancreatology. 2016; 16:829-38.

10. Huang Y, Simms AE, Mazur A, Wang S, León NR, Jones B, Aziz N, Kelly T. Fibroblast activation protein- $\alpha$ promotes tumor growth and invasion of breast cancer cells through non-enzymatic functions. Clin Exp Metastasis. 2011; 28:567-79.

11. Yang W, Han W, Ye S, Liu D, Wu J, Liu H, Li C, Chen H. Fibroblast activation protein- $\alpha$ promotes ovarian cancer cell proliferation and invasion via extracellular and intracellular signaling mechanisms. Exp Mol Pathol. 2013; 95:105-10.

12. Teichgräber V, Monasterio C, Chaitanya K, Boger R, Gordon K, Dieterle T, Jäger D, Bauer S. Specific inhibition of fibroblast activation protein (FAP)-alpha prevents tumor progression in vitro. Adv Med Sci. 2015; 60:264-72

13. Scott AM, Wiseman G, Welt S, Adjei A, Lee FT, Hopkins W, Divgi CR, Hanson LH, Mitchell P, Gansen DN, Larson SM, Ingle JN, Hoffman EW, et al. A Phase I doseescalation study of sibrotuzumab in patients with advanced or metastatic fibroblast activation protein-positive cancer. Clin Cancer Res. 2003; 9:1639-47.

14. Jackson RC. Contributions of protein structure-based drug design to cancer chemotherapy. Semin Oncol. 1997; 24:164-72.

15. Augoff K, Hryniewicz-Jankowska A, Tabola R, Czapla L, Szelachowski P, Wierzbicki J, Grabowski K, Sikorski AF. Upregulated expression and activation of membrane-associated proteases in esophageal squamous cell carcinoma. Oncol Rep. 2014; 31:2820-6.

16. Roberts EW, Deonarine A, Jones JO, Denton AE, Feig C, Lyons SK, Espeli M, Kraman M, McKenna B, Wells RJ, Zhao Q, Caballero OL, Larder R, et al. Depletion of stromal cells expressing fibroblast activation protein- $\alpha$ from skeletal muscle and bone marrow results in cachexia and anemia. J Exp Med. 2013; 210:1137-51.

17. Dolznig H, Schweifer N, Puri C, Kraut N, Rettig WJ, Kerjaschki D, Garin-Chesa P. Characterization of cancer stroma markers: in silico analysis of an mRNA expression database for fibroblast activation protein and endosialin. Cancer Immun. 2005;5:10.

18. Lee KN, Jackson KW, Christiansen VJ, Dolence EK, McKee PA. Enhancement of fibrinolysis by inhibiting enzymatic cleavage of precursor $\alpha 2$-antiplasmin. J Thromb Haemost. 2011; 9:987-96.

19. Kalluri R, Zeisberg M. Fibroblasts in cancer. Nat Rev Cancer. 2006; 6:392-401.

20. Beach JA, Aspuria PJ, Cheon DJ, Lawrenson K, Agadjanian H, Walsh CS, Karlan BY, Orsulic S. Sphingosine kinase 1 is required for TGF- $\beta$ mediated fibroblast-to-myofibroblast differentiation in ovarian cancer. Oncotarget. 2016; 7:4167-4182. doi: 10.18632/ oncotarget.6703.

21. Chen H, Yang WW, Wen QT, Xu L, Chen M. TGF-beta induces fibroblast activation protein expression; fibroblast activation protein expression increases the proliferation, adhesion, and migration of HO-8910PM. Exp Mol Pathol. 2009; 87:189-94.

22. Cohen SJ, Alpaugh RK, Palazzo I, Meropol NJ, Rogatko A, $\mathrm{Xu}$ Z, Hoffman JP, Weiner LM, Cheng JD. Fibroblast activation protein and its relationship to clinical outcome in pancreatic adenocarcinoma. Pancreas. 2008; 37:154-8.

23. Fluge $\varnothing$, Bruland $O$, Akslen LA, Lillehaug JR, Varhaug JE. Gene expression in poorly differentiated papillary thyroid carcinomas. Thyroid. 2006; 16:161-75.

24. Goscinski MA, Suo ZH, Nesland JM, Chen WT, Zakrzewska M, Wang J, Zhang S, Flørenes VA, Giercksky KE. Seprase, dipeptidyl peptidase IV and urokinase-type plasminogen activator expression in dysplasia and invasive squamous cell carcinoma of the esophagus. A study of 229 cases from Anyang Tumor Hospital, Henan Province, China. Oncology. 2008; 75:49-59.

25. Kennedy A, Dong H, Chen D, Chen WT. Elevation of seprase expression and promotion of an invasive phenotype by collagenous matrices in ovarian tumor cells. Int J Cancer. 2009; 124:27-35.

26. Mori Y, Kono K, Matsumoto Y, Fujii H, Yamane T, Mitsumata M, Chen WT. The expression of a type II transmembrane serine protease (Seprase) in human gastric carcinoma. Oncology. 2004; 67:411-9.

27. Tillmanns J, Widera C, Habbaba Y, Galuppo P, Kempf T, Wollert KC, Bauersachs J. Circulating concentrations of fibroblast activation protein $\alpha$ in apparently healthy individuals and patients with acute coronary syndrome as assessed by sandwich ELISA. Int J Cardiol. 2013; 168:3926-31.

28. Aoyama A, Chen WT. A $170-\mathrm{kDa}$ membrane-bound protease is associated with the expression of invasiveness by human malignant melanoma cells. Proc Natl Acad Sci USA. 1990; 87:8296-300.

29. Chen D, Kennedy A, Wang JY, Zeng W, Zhao Q, Pearl M, Zhang M, Suo Z, Nesland JM, Qiao Y, Ng AK, Hirashima N, Yamane T, et al. Activation of EDTA-resistant gelatinases in malignant human tumors. Cancer Res. 2006; 66:9977-85.

30. Henry LR, Lee HO, Lee JS, Klein-Szanto A, Watts P, Ross EA, Chen WT, Cheng JD. Clinical implications of fibroblast activation protein in patients with colon cancer. Clin Cancer Res. 2007; 13:1736-41.

31. O'Brien P, O'Connor BF. Seprase: an overview of an important matrix serine protease. Biochim Biophys Acta. 2008; 1784:1130-45.

32. Kraman M, Bambrough PJ, Arnold JN, Roberts EW, Magiera L, Jones JO, Gopinathan A, Tuveson DA, Fearon DT. Suppression of antitumor immunity by stromal cells expressing fibroblast activation protein-alpha. Science. 2010; 330:827-30. 
33. Yang X, Lin Y, Shi YH, Li B, Liu W, Yin W, Dang Y, Chu Y, Fan J, He R. FAP promotes immunosuppression by cancerassociated fibroblasts in the tumor microenvironment via STAT3-CCL2 signaling. Cancer Res. 2016; 76:4124-35.

34. Park JE, Lenter MC, Zimmermann RN, Garin-Chesa P, Old LJ, Rettig WJ. Fibroblast activation protein, a dual specificity serine protease expressed in reactive human tumor stromal fibroblasts. J Biol Chem. 1999; 274:36505-12.

35. Uitte de Willige S, Malfliet JJ, Janssen HL, Leebeek FW, Rijken DC. Increased N-terminal cleavage of alpha-2antiplasmin in patients with liver cirrhosis. J Thromb Haemost. 2013; 11:2029-36.

36. Lee KN, Jackson KW, Christiansen VJ, Lee CS, Chun JG, McKee PA. Antiplasmin-cleaving enzyme is a soluble form of fibroblast activation protein. Blood. 2006; 107:1397-404.

37. Collins PJ, McMahon G, O'Brien P, O'Connor B. Purification, identification and characterisation of seprase from bovine serum. Int J Biochem Cell Biol. 2004; 36:2320-33.

38. Keane FM, Yao TW, Seelk S, Gall MG, Chowdhury S, Poplawski SE, Lai JH, Li Y, Wu W, Farrell P, Vieira de Ribeiro AJ, Osborne B, Yu DM, et al. Quantitation of fibroblast activation protein (FAP)-specific protease activity in mouse, baboon and human fluids and organs. FEBS Open Bio. 2013; 4:43-54.
39. Uitte de Willige S, Malfliet JJ, Deckers JW, Dippel DW, Leebeek FW, Rijken DC. Plasma levels of soluble fibroblast activation protein in arterial thrombosis: determinants and cleavage of its substrate alpha-2-antiplasmin. Int J Cardiol. 2015; 178:105-10.

40. Wang XP, Li XH, Zhang L, Lin JH, Huang H, Kang T, Mao MJ, Chen H, Zheng X. High level of serum apolipoprotein A-I is a favorable prognostic factor for overall survival in esophageal squamous cell carcinoma. BMC Cancer. 2016; 16:516.

41. Kotani K, Sekine Y, Ishikawa S, Ikpot IZ, Suzuki K, Remaley AT. High-density lipoprotein and prostate cancer: an overview. J Epidemiol. 2013; 23:313-9.

42. Edge SB, Compton CC. The American Joint Committee on Cancer: the 7th edition of the AJCC cancer staging manual and the future of TNM. Ann Surg Oncol 2010; 17:1471-1474. 